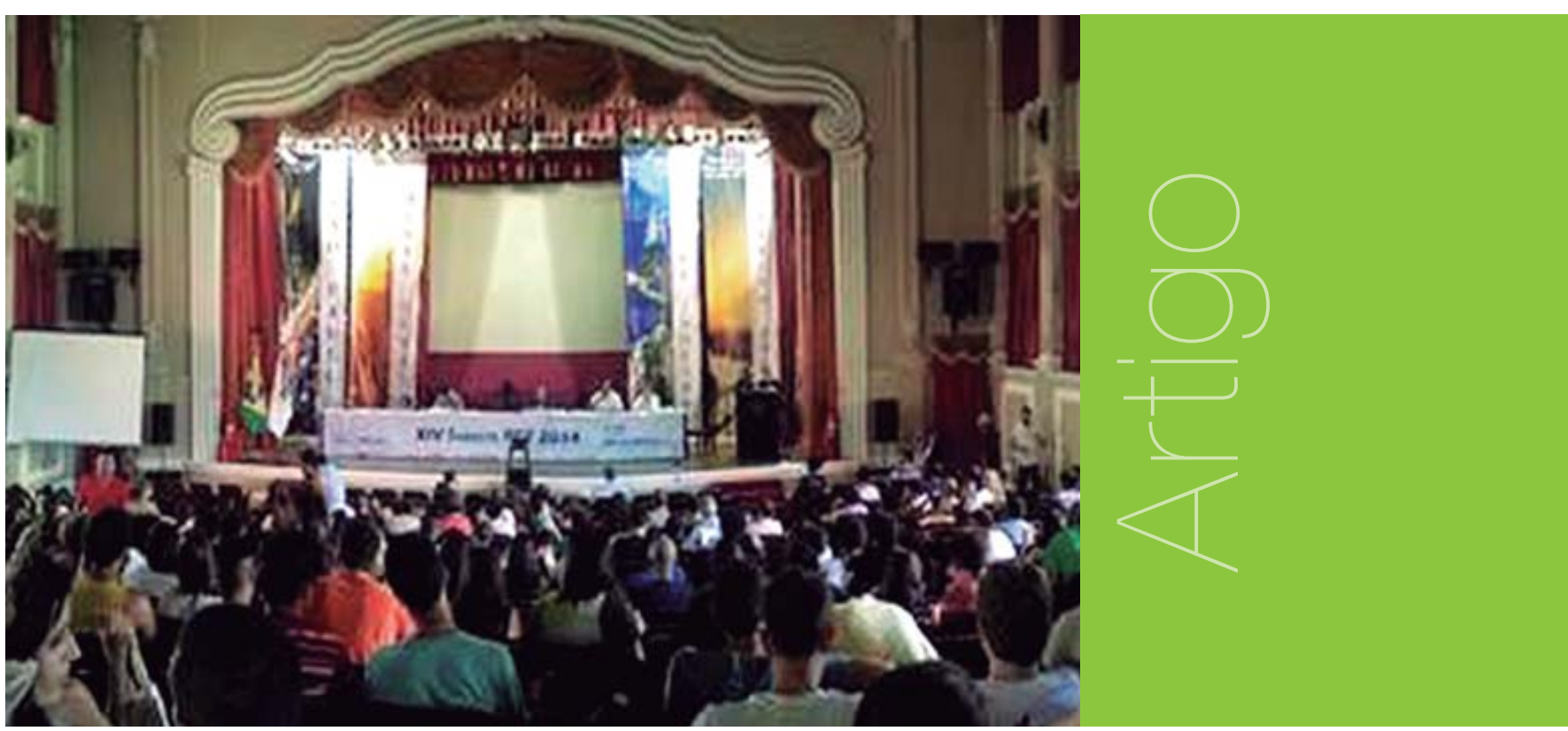

\title{
Potencialidades e fragilidades do Programa de Educação Tutorial: percepções de acadêmicos
}

\author{
Patrícia Rossetti Dearo - patriciardearo@hotmail.com \\ Jessica Tamy Oliveira Nakayama² - jessieto.ufsp@gmail.com \\ Rosana Aparecida Salvador Rossit ${ }^{3}$ - rorossit@hotmail.com
}

\section{RESUMO}

Frente aos desafios refletidos na implantação, manutenção e sustentabilidade do Programa de Educação Tutorial (PET), paralelamente à inconstância no seguimento das normas e de mudanças nas políticas educacionais, torna-se relevante analisar, na percepção dos acadêmicos, a influência desse programa na formação profissional. Para isso, realizou-se uma pesquisa qualitativa com participantes de encontros do PET, regional e nacional, o que possibilitou o registro de opiniões sobre as potencialidades, fragilidades e sugestões em relação ao programa. Os relatos foram categorizados e a partir deles pode-se observar que os participantes do programa costumam destacar as competências desenvolvidas, bem como: reconhecimento institucional, fortalecimento político, bolsa e recursos de custeio.

\section{PALAVRAS-CHAVE}

Ensino superior. Formação profissional. Educação tutorial.

\footnotetext{
1 Nutricionista formada pela Universidade Federal de São Paulo e egressa do PET Saúde da Criança.

2 Terapeuta Ocupacional formada pela Universidade Federal de São Paulo e egressa do PET Saúde da Criança.

3 Professor Associado do Departamento Saúde, Educação e Sociedade e Tutora do PET Saúde da Criança da Universidade Federal de São Paulo - Baixada Santista.
} 


\section{ABSTRACT}

The challenges reflected in the implementation, maintenance and sustainability of the Tutorial Education Program (PET), together with fickleness following the rules and changes in education policy, it is important to analyze, in the perception of academics, the influence of the Program Tutorial education in vocational training. We conducted a qualitative research with participants from PET meetings, regional and national levels, through a protocol which allowed the registration of views on the potential, weaknesses and suggestions for PET. From the analysis of content, the reports were categorized. The results show a positive outlook for PET especially developed skills, however, other fundamental aspects should be reviewed, as institutional recognition, political strengthening, scholarship and costing resources.

\section{KEYWORDS}

Higher education. Vocational training. Tutorial Education.

\section{Introdução}

Em 1979, a Coordenação de Aperfeiçoamento de Pessoal de Nível Superior (CAPES) criou 0 Programa Especial de Treinamento com o objetivo de aprimorar o ensino superior brasileiro. Em 1999, o programa foi transferido para a Secretaria de Educação Superior do Ministério da Educação (SESu/MEC) e, em 2004, passou a ser denominado Programa de Educação Tutorial (PET) (BRASIL, 2006). A troca do nome do programa marcou uma mudança de concepção, tornando-o mais sólido para o desenvolvimento de suas atividades.

0 programa é formado por grupos difundidos por todo Brasil, em instituições de ensino superior públicas e privadas, constituídos por, no máximo, 12 estudantes bolsistas e até seis não bolsistas, acompanhados por um professor tutor, sendo que todos os participantes do programa (alunos e professores) são conhecidos pelo termo "petianos". Os grupos são responsáveis por desenvolver atividades extracurriculares, tendo como requisito a indissociabilidade entre ensino, pesquisa e extensão (MARTIN, 2005). As práticas que compõem o programa têm como objetivo propiciar ao estudante vivências e experiências para além do seu curso de graduação, favorecendo a formação acadêmica e a prática profissional (BRASIL, 2006).

Como forma de nortear as atividades realizadas no PET, o Manual de Orientações Básicas (MOB) foi desenvolvido para orientar o funcionamento do programa e estabelecer um padrão nacional para os grupos (BRASIL, 2006).

Um dos aspectos positivos do programa corresponde à ênfase no trabalho conjunto de estudantes e tutores planejando, organizando, realizando e avaliando todas as atividades desenvolvidas pelo grupo. Além disso, ressalta-se o fato de a equipe não precisar tratar de assunto relacionado à linha de pesquisa do professor tutor nem do curso de graduação em que 0 estudante está matriculado (MARTIN, 2005).

0 grupo tutorial se caracteriza pela presença de um tutor, cuja missão é estimular a aprendizagem ativa dos seus membros por meio de vivências, reflexões e discussões. Ele é o responsável por supervisionar o planejamento e as atividades e indicar o melhor caminho de uma aprendizagem efetiva e relevante aos seus estudantes (BRASIL, 2006).

0 método tutorial, em contraste com 0 ensino centrado principalmente na memorização passiva de fatos e informações, permite o desenvolvimento de competências de resolução de problemas e pensamento crítico entre os bolsistas. Ao mesmo tempo em que oportuniza aos estudantes tornarem-se cada vez mais independentes em relação à administração de suas necessidades de aprendizagem.

Ao desenvolver ações de ensino, pesquisa e extensão de maneira articulada, o PET permite o compartilhamento e ampliação de saberes, tanto de professores tutores e bolsistas quanto dos demais estudantes do curso, proporcionando-Ihes uma compreensão mais integral e interdisciplinar em contraposição à fragmentação da formação que, por vezes, prioriza um dos 
eixos de ação. Ao mesmo tempo, a multiplicidade de experiências contribui para reduzir os riscos da especialização ainda na graduação.

0 PET é um programa governamental com mais de 35 anos, o que impõe a necessidade de aprimoramento e reformulação, com a participação dos atores envolvidos. A proposta é que o PET se constitua em um elemento estratégico para refletir, conceituar e operacionalizar a educação tutorial e, dessa forma, discutir o ensino, a pesquisa e a extensão, compreendendo esses conceitos dialeticamente e trabalhando-os como aspectos balizadores do programa (BRASIL, 2006; MARTINS; KETZER, 2008).

0 PET Saúde da Criança foi criado em 2010, tendo como objetivo promover o desenvolvimento infantil e prevenir agravos no âmbito social, da saúde e educação. Constituído por uma equipe multidisciplinar, com estudantes dos seis cursos da saúde da UNIFESP - câmpus Baixada Santista (Educação Física, Fisioterapia, Nutrição, Psicologia, Serviço Social e Terapia Ocupacional), o PET Saúde da Criança articula os princípios da indissociabilidade entre ensino, pesquisa e extensão de modo a possibilitar espaços e oportunidades de conhecimento e aprendizagens que ultrapassem os limites físicos da estrutura acadêmica universitária.

A partir das experiências vividas pelos integrantes do PET Saúde da Criança e da escassez de literatura sobre 0 tema, percebeu-se a necessidade de produzir materiais sobre 0 PET, na perspectiva dos participantes do programa. Dessa forma, buscou-se conhecer a percepção dos acadêmicos com relação às possíveis potencialidades e fragilidades encontradas no Programa de Educação Tutorial das diferentes regiões do Brasil.

\section{Metodologia}

Os participantes dos dois eventos - XIV Encontro Regional dos Grupos PET da região Sudeste (Sudeste PET) realizado em abril de 2014, na cidade de Seropédica-RJ, e o XIX Encontro Nacional dos Grupos PET (EnaPET), em agosto de 2014, em Santa Maria-RS - foram convidados a fornecer informações sobre as suas percepções com relação ao PET. A amostra foi constituída por 189 acadêmicos vinculados a grupos PET das regiões Nordeste, Norte, Centro-oeste, Sudeste e Sul do Brasil, os quais responderam a enquete, após manifestar a concordância livre e esclarecida.

0 projeto foi aprovado pelo Comitê de Ética em Pesquisa da Universidade Federal de São Paulo sob nº 0720/11 e constitui-se como um subprojeto do PET Saúde da Criança/Unifesp, Baixada Santista.

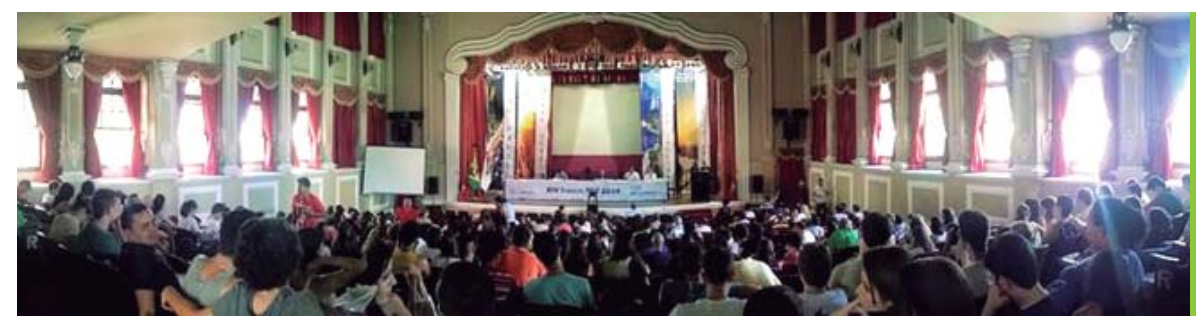

Figura 1: Foto oficial do XIV Sudeste PET.

Fonte: http://r1.ufrri.br/ petsi/sudestepetri2014

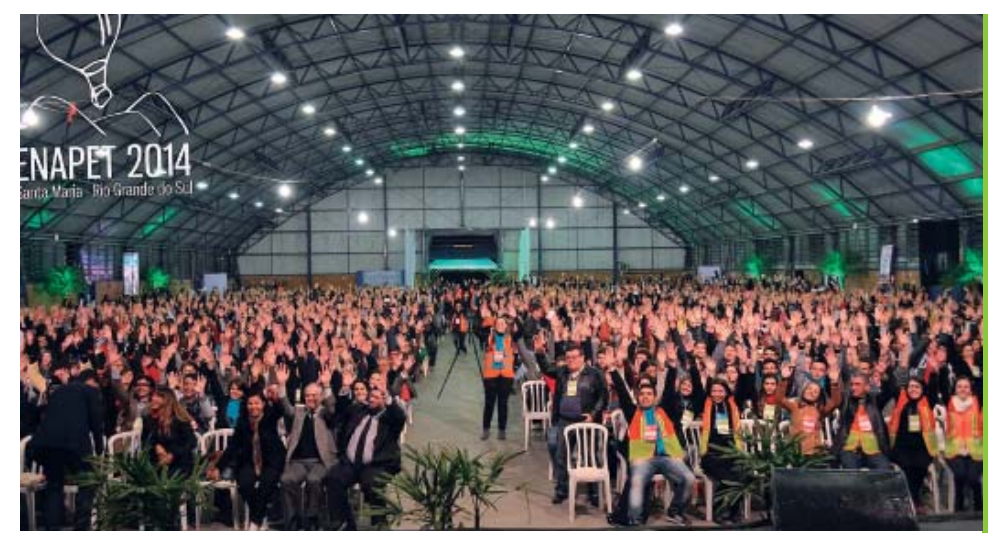


Dois modelos de questionários foram aplicados em momentos diferentes. A primeira coleta de dados foi realizada no Sudeste PET 2014 onde foi aplicado um questionário aberto que solicitava informações pessoais, institucionais e do grupo PET ao qual o participante estava vinculado. Os participantes eram convidados a destacar os aspectos positivos relacionados ao tema no item: "Que bom", a apontar os aspectos positivos relacionados ao PET em "Que pena" e, por fim, em "Que tal" deixar sugestões A Fig. 3 apresenta o modelo de questionário.
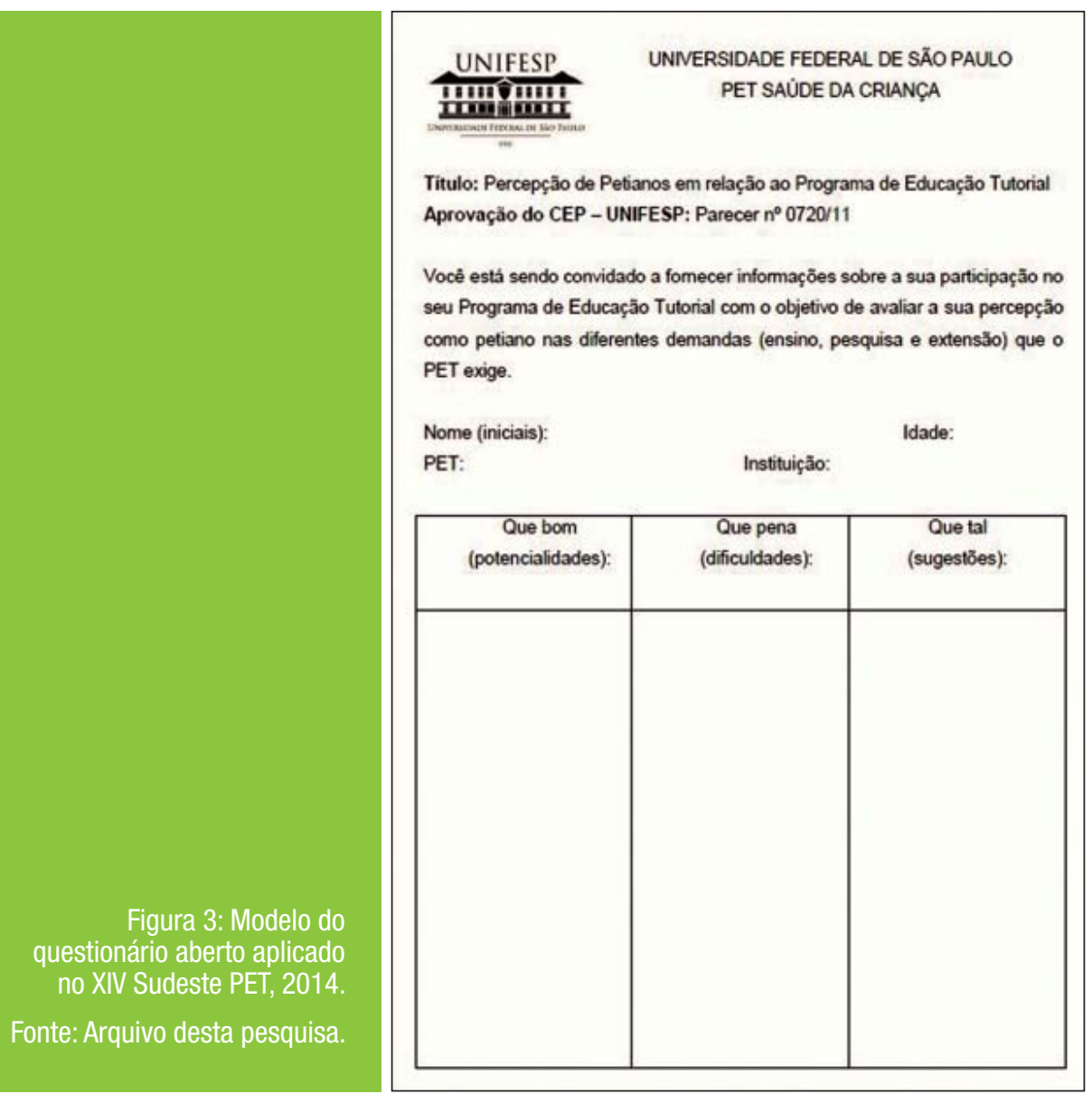

Os registros das percepções foram analisados qualitativamente por meio da análise de conteúdo, na modalidade temática. A escolha da análise de conteúdo se deu porque ela permite descobrir o que está por trás dos conteúdos manifestos, indo além das aparências do que está sendo comunicado. No caso da análise temática, como o próprio nome indica, o tema é o juízo central, que pode ser representado através de uma palavra, frase ou resumo (MINAYO; DESLANDES; GOMES, 2010).

Os textos descritos pelos acadêmicos foram organizados em três documentos: potencialidades, dificuldades e sugestões. Cada um deles foi lido e (re)lido, separadamente, em busca de significados. A leitura e releitura do material escrito para a impregnação dos sentidos permitiu a identificação das categorias emergentes dos conteúdos expressos.

Os passos estabelecidos para a análise temática consistiram na identificação das Unidades de Contexto (UC), com suas respectivas Unidades de Registro (UR). A UC é a parte mais ampla do conteúdo, ou seja, o contexto do qual faz parte a mensagem que será analisada. A UR é a menor parte do conteúdo e pode incluir a palavra, o tema, o personagem e/ou 0 item.

A segunda coleta de dados foi realizada no EnaPET 2014. Além da aplicação do questionário aberto para ampliação da amostra inicial, houve aplicação de um instrumento misto, no qual os petianos deveriam assinalar as opções a partir de um checklist organizado com as principais categorias obtidas do questionário aberto do Sudeste PET e espaço aberto para "comentários". A Fig. 4 apresenta o modelo do instrumento. 

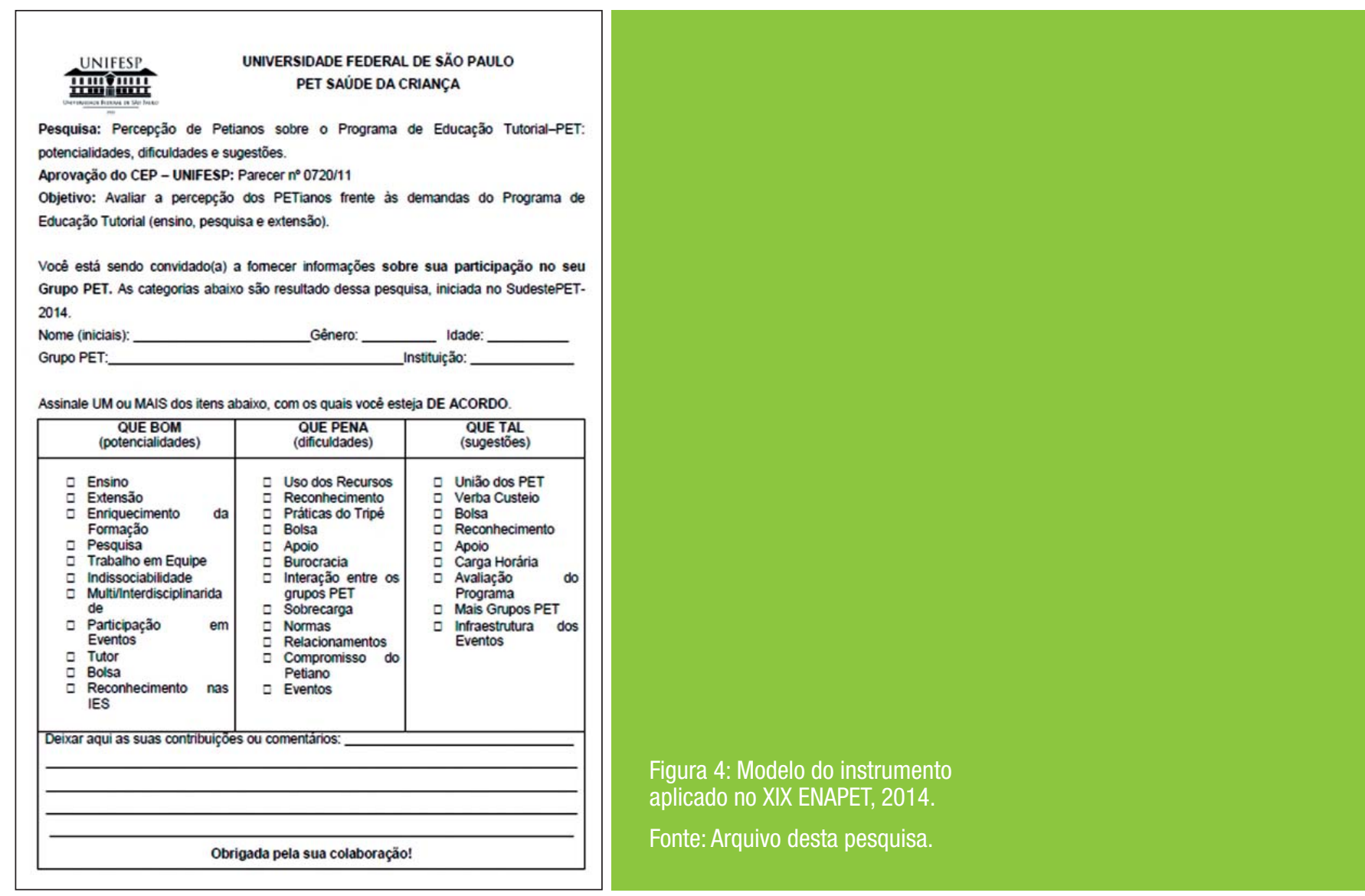

\section{Resultados e discussão}

Responderam ao questionário 189 participantes dos dois eventos realizados em 2014. Os acadêmicos eram vinculados a 29 Instituições de Ensino Superior (IES) brasileiras e a 64 grupos PET, distribuídos conforme dados da Tabela 1.

\begin{tabular}{|c|c|c|}
\hline Região & Instituições de Ensino Superior & $\begin{array}{l}\text { Número de } \\
\text { respondentes }\end{array}$ \\
\hline Nordeste & $\begin{array}{l}3 \text { instituições } \\
\text { (UFMA, UFC e Escola Bahiana de Medicina e Saúde Pública) }\end{array}$ & 6 \\
\hline Norte & $\begin{array}{l}1 \text { instituição } \\
\text { (Unifap) }\end{array}$ & 4 \\
\hline Centro-oeste & $\begin{array}{l}1 \text { instituição } \\
\text { (UFMT) }\end{array}$ & 7 \\
\hline Sudeste & $\begin{array}{c}18 \text { instituições } \\
\text { (Unifal, UFTM, IFTM, UFMG, UFJF, UFU, UFV, UFOP, UFSJ, UFES, } \\
\text { Ufrrj UFF, UERJ, Unesp, USP, Ufscar, Unifesp e PUC) }\end{array}$ & 139 \\
\hline Sul & $\begin{array}{c}6 \text { instituições } \\
\text { (UEL, UEM, UFPR, UFFS, Ufpele Unipampa) }\end{array}$ & 33 \\
\hline Total & 29 & 189 \\
\hline
\end{tabular}

Tabela 1: Caracterização das IES que acolhem os grupos PETs.

Fonte: Dados obtidos com o desenvolvimento da pesquisa PET Saúde da Criança/Unifesp, 2014.

A seguir, apresentam-se os resultados referentes às potencialidades, fragilidades e sugestões, que foram categorizados a partir das análises das opiniões coletadas nos instrumentos.

A Figura 5 apresenta a percepção dos participantes em relação à categoria potencialidades. As subcategorias emergentes foram as seguintes: ensino, extensão, enriquecimento da formação, pesquisa, trabalho em equipe, indissociabilidade, multi/interdisciplinaridade, participação em eventos, tutor, bolsa e reconhecimento nas IES. 
Figura 5: Quantidade

de respondentes e

as subcategorias que

emergiram da categoria

"potencialidades".

Fonte: Dados obtidos com 0 desenvolvimento da pesquisa

PET Saúde da Criança/ Unifesp, 2014.

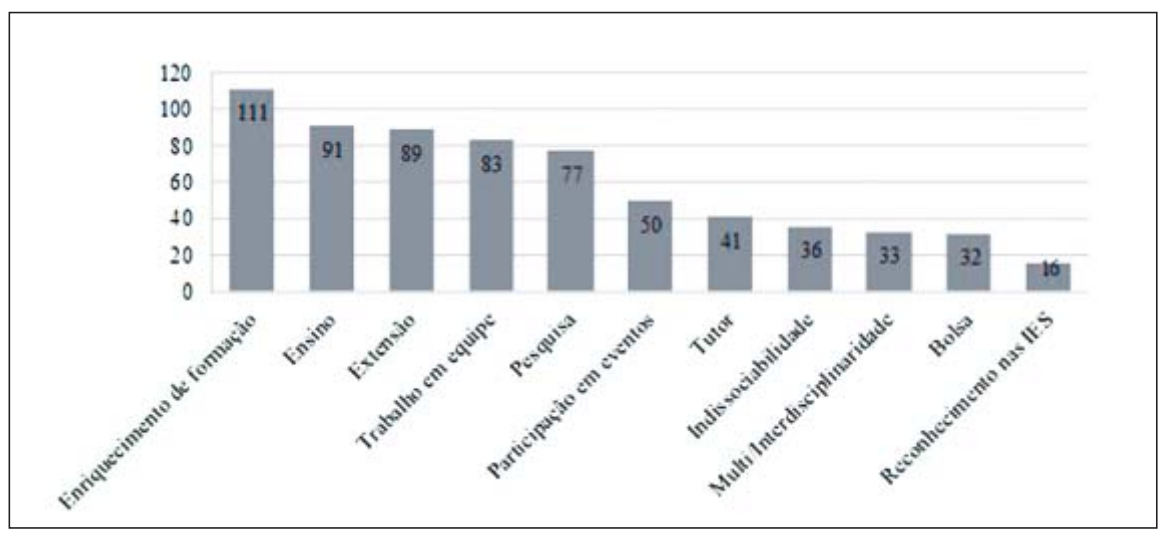

Nota-se que as subcategorias "enriquecimento da formação" e "ensino" foram as mais citadas pelos participantes. De acordo com um dos participantes da pesquisa, o PET "coloca 0 aluno da graduação frente a dificuldades que encontrará quando formado. Fomenta 0 senso crítico como aluno". Outro participante destacou o "desenvolvimento de habilidades não exploradas pela graduação; aplicação de conteúdo aprendido em salas de aula; visão diferenciada dos demais estudantes de graduação; aprendizado indissociável”.

Souza e Júnior (2015) destacam que os estudantes que participam do PET demoram menos tempo para concluir 0 curso da graduação, possuem menor taxa de evasão e conseguem se inserir no mundo do trabalho mais rapidamente e/ou seguem em processo de qualificação, por meio de cursos de pós-graduação, quando comparados com estudantes que não participaram do PET.

Outra subcategoria amplamente citada foi a "extensão", que se refere às atividades realizadas em ambientes externos ou internos à universidade e têm como alvo as ações para a comunidade.

A extensão universitária deve existir, pois é uma forma de interação entre a comunidade em que a universidade está inserida, devendo haver troca de saberes em que os acadêmicos levam os seus conhecimentos e/ou assistências para a comunidade e ela o retribui com os seus saberes culturais e específicos (NUNES; SILVA, 2011).

Destaca-se a seguir o relato de um dos participantes que ilustra os achados:

\begin{abstract}
Acredito que a prática do ensino, pesquisa e extensão enriquece o jovem em um dos desafios mais importantes de sua vida: 0 curso de graduação. A formação de valores comprometidos com 0 ambiente social, com a sustentabilidade dos seus recursos e 0 desenvolvimento das potencialidades pessoais tornam-se destaque para o mercado de trabalho e torna-se um cidadão consciente de que o mundo é modificado diariamente por ações sólidas no ambiente que o cerca. Fonte: Dados obtidos com o desenvolvimento da pesquisa PET Saúde da Criança/Unifesp, 2014.
\end{abstract}

A Figura 6 apresenta as subcategorias emergentes da categoria dificuldades: uso dos recursos, reconhecimento, prática do tripé, bolsa, apoio, burocracia, interação entre os grupos PET, sobrecarga, normas, relacionamentos, compromisso do petiano e eventos.

Figura 6: Quantidade de respondentes e as subcategorias que emergiram da categoria "dificuldades".

Fonte: Dados obtidos com o desenvolvimento da pesquisa PET Saúde da Criança/Unifesp, 2014.

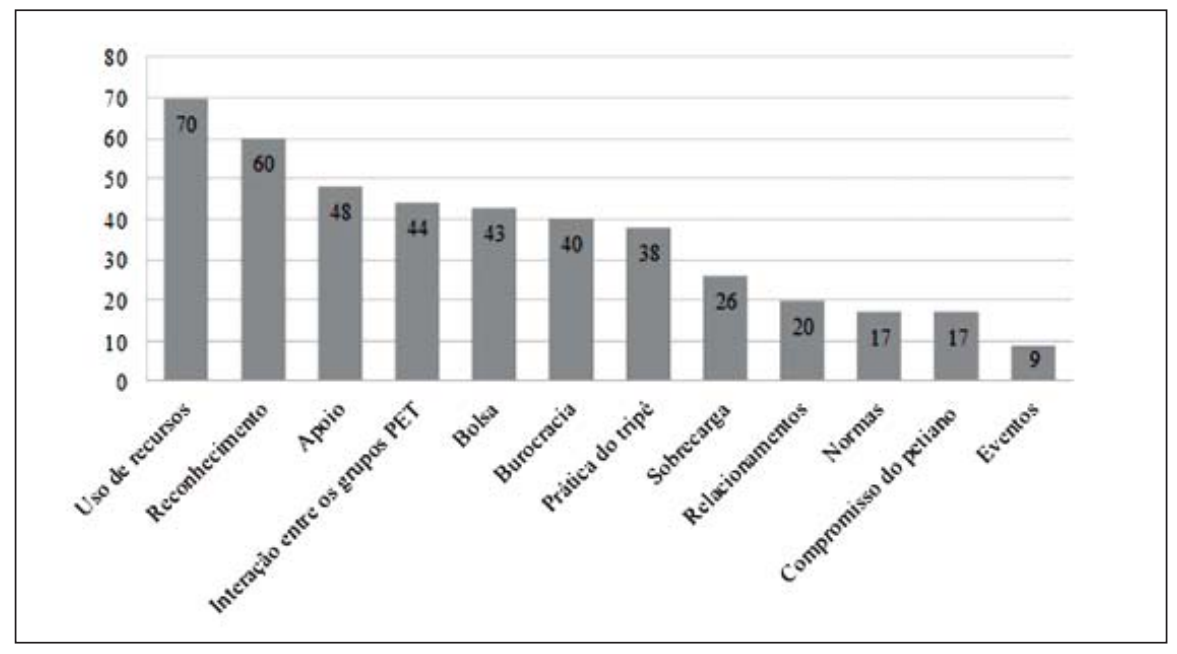


Nota-se que na categoria dificuldades, as subcategorias mais citadas foram "uso de recursos" e "reconhecimento". Seguidos por "apoio", que faz referência tanto à instituição que o participante está inserido quanto ao apoio governamental.

Alguns participantes relataram "dificuldade no que tange ao financiamento de congressos, pesquisas, materiais de uso permanente" e "desvalorização como programa, em nível governamental e institucional".

Dentre as dificuldades podemos destacar aquela relacionada com o tempo/organização que se refere a conciliar atividades do PET, que demanda carga horária de 20 horas semanais, com atividades curriculares. Dificuldades de organização do grupo pela falta de horários livres comuns em meio à graduação e à necessidade do desenvolvimento de ações no âmbito do ensino, pesquisa e extensão, o que demanda muita organização, conhecimento e integração entre os integrantes do grupo PET. Assim como foi relatado por um dos participantes:

Minha principal dificuldade é a exigência em relação a esse programa. Hoje vivo em função do PET, pois o tempo é curto e vida social é complicado, pois o curso da graduação já exige demais. E atraso nas bolsas. Fonte: Dados obtidos com o desenvolvimento da pesquisa PET Saúde da Criança/Unifesp, 2014.

A Figura 7 apresenta as subcategorias emergentes da categoria sugestões: união dos PETs, verba custeio, bolsa, reconhecimento, apoio, carga horária, avaliação do programa, novos grupos PETs e infraestrutura dos eventos.

Nota-se que 0 aumento da verba de custeio e o reconhecimento institucional ganham destaque nessa dimensão de análise, mas também foram aspectos relatados nas categorias anteriores.

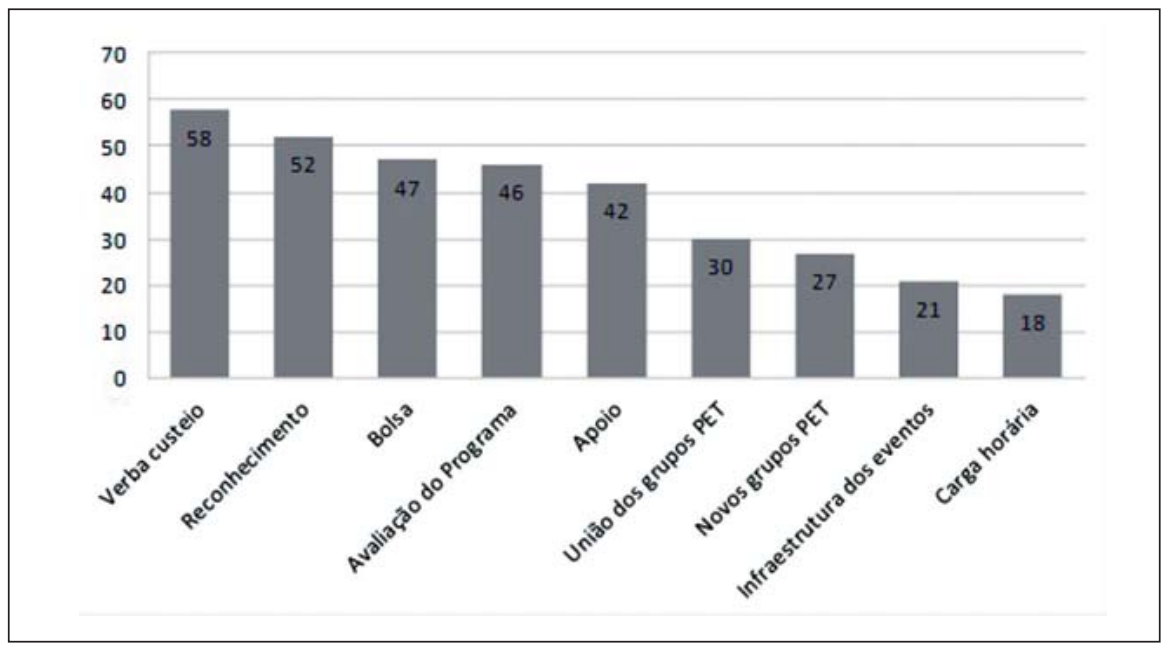

Figura 7: Quantidade de respondentes e

as subcategorias que emergiram da categoria "sugestões".

Fonte: Dados obtidos

com 0 desenvolvimento da pesquisa PET Saúde daCriança/Unifesp, 2014.

A educação superior vem passando por transformações nos últimos anos, sendo uma delas o processo de democratização com a criação de vários programas de acesso e assistência estudantil, entendendo-a como uma política social seletiva que só poderá atender a um determinado grupo de estudantes que se enquadre no perfil e nos critérios definidos pelo programa.

Destaca-se que a oportunidade de ser contemplado com bolsa é fundamental para a permanência de muitos estudantes no ensino superior, almejando a conclusão da graduação com qualidade e igualdade de oportunidade.

É evidente que 0 critério relacionado à nota mínima que o candidato deve ter para poder participar do PET está relacionado à obtenção de bolsa. No entanto, isso não significa que o candidato não seja adequado para o programa, o qual, inclusive, pode contribuir para a melhoria do desempenho desse aluno em sala de aula. Fonte: Dados obtidos com o desenvolvimento da pesquisa PET Saúde da Criança/Unifesp, 2014.

Diante dos resultados expostos, nota-se que o PET torna-se também um local de aprendizagem significativa e reflexiva, que incita o estudante a pensar e problematizar o ambiente em que está inserido, tendo que pensar e buscar formas de melhorias para a sua atuação como petiano. 
Dessa forma, é possível perceber a importância da percepção dos estudantes diretamente envolvidos com o programa como uma ferramenta para a melhoria da formação universitária, podendo fomentar debates acerca do PET e da inserção e disseminação dos conhecimentos na formação universitária e em ações na e para a comunidade.

Para Kuenzer (2000), o método tutorial do PET se fundamenta na atividade prática como ponto de partida para a produção do conhecimento, ou seja, em seu trabalho, compreendido como todas as formas de atividade humana através das quais o homem apreende, compreende e transforma as circunstâncias ao mesmo tempo em que é transformado por elas. Não há dúvidas que a dinâmica da educação superior, assim como 0 desenvolvimento científico, cultural e tecnológico faça ressurgir ideias e crie novos argumentos para alimentar o debate em torno do PET. Isso é importante e deve ser compreendido como defesa de pontos de vista e de expectativas que pretendem, acima de tudo, produzir um programa acadêmico cada vez mais integrado aos avanços do mundo moderno e compreendido pela sociedade que o financia (MARTINS; KETZER, 2008).

\section{Considerações finais}

A base de conhecimentos gerada na presente pesquisa aponta para uma visão positiva em relação ao PET, que fornece ao acadêmico a oportunidade de se aproximar da indissociabilidade entre ensino, pesquisa e extensão na graduação, tão importante para o seu enriquecimento pessoal e profissional, nos âmbitos da aprendizagem, do trabalho em equipe, da experiência e contato com a comunidade e da possibilidade de se desenvolver projetos e pesquisas. Embora os resultados expostos possam levantar possíveis discussões que são pertinentes ao aprimoramento do PET, não foi possível confrontá-los com resultados de outros estudos, já que há uma escassez de investigações recentes que questionem as atividades realizadas, dificuldades encontradas, impactos do programa na formação dos acadêmicos, dentre outros aspectos importantes. Dessa forma, torna-se necessária a mobilização dos grupos PET, no que diz respeito à produção e à disseminação de conhecimentos que retratem o programa na sua real vivência, possibilitando assim, o seu fortalecimento.

É necessário que os resultados apontados e o campo político do programa sejam fortalecidos para que se torne possivel vislumbrar novas ações e se construir conjuntamente os espaços e propostas para o desenvolvimento do PET, almejando reconhecimento por parte do governo, da comunidade acadêmica e da sociedade.

Portanto, é de extrema relevância a avaliação continuada do programa e estudos que considerem não só a percepção dos acadêmicos, mas também a percepção de tutores e egressos. Tornar essa avaliação uma pesquisa científica confere visibilidade a essas questões e contribui para 0 desenvolvimento e aprimoramento de aspectos relacionados ao PET.

\section{Referências}

BRASIL. Ministério da Educação. Manual de Orientações Básicas PET. Ministério da Educação. Secretaria de Educação Superior - SESu. Disponível em: <http://portal.mec.gov.br/ sesu/arquivos/pdf/PETmanual.pdf>. Acesso em 28 de maio de 2016.

KUENZER, A. Ensino Médio: construindo uma proposta para os que vivem do trabalho. São Paulo: Editora Cortez, 2000.

MARTIN, M. G. M. B. 0 Programa de Educação Tutorial - PET: formação ampla na graduação. 2005. 108 f. Dissertação (Mestrado em Educação) - Universidade Federal do Paraná, Curitiba. 2005.

MARTINS, I. M. L.; KETZER, S. M. Programa de Educação Tutorial: estratégia para 0 desenvolvimento da graduação. 1. ed. Brasília: Brasil Tropical, 2008.

MINAYO, M. C. S.; DESLANDES, R.; GOMES, S. F. Pesquisa social: teoria, método e criatividade. 29. ed. Petrópolis: Vozes, 2010. 
NUNES, A. L. P. F.; SILVA, M. B. C. A extensão universitária no ensino superior e a sociedade. Malestar e Sociedade, Barbacena, n. 7, p. 119-133, jul./dez. 2011. Disponível em: < http://www. uemg.br/openjournal/index.php/malestar/article/view/60> Acesso em: 21 de Agosto de 2016.

SOUZA, R. M.; JÚNIOR, S. R. G. Programa de Educação Tutorial: avanços na formação em Física no Rio Grande do Norte. Revista Brasileira de Ensino de Física, v.37, n. 1, p. 1501-05, 2015. Disponível em: < http://www.scielo.br/pdf/rbef/v37n1/0102-4744-rbef-37-01-1501.pdf> Acesso em: 28 de maio de 2016. 